SECTION THREE

The Student Learning Process 


\title{
What to Cover and When
}

\author{
By Philip M. Sadler
}

Science Education Department, Harvard Smithsonian Center for Astrophysics and Harvard Graduate School of Education, Cambrdige MA, USA

Imagine trying to teach reading to students who do not know the alphabet or driving to someone who does not know the purpose of the brake. As teachers, we have a view of what the fundamental ideas that our field are and make decisions about their coverage and order in our courses. Yet, research shows that students rarely have the foundation that we expect; they hold misconceptions about the physical world that actually inhibit the learning of many scientific concepts. Moreover, the metaphors that we employ for building student understanding: reliving the historical development of the field, journeying from the closest to farthest reaches of the universe, and observing the objects in the sky, are only based on our own beliefs in their effectiveness. Empirical evidence shows that they are of little value; there is rarely any lasting change in students' conceptual understanding in science. Yet, by testing large populations, one can tease out the relative difficulty of astronomical conceptions, which misconceptions inhibit understanding of scientific ideas, and which concepts are prerequisites for others. These relationships allow the determination of an intrinsic structure of astronomical concepts, the way in which novices to experts appear to progress naturally through to an understanding of the field. Such a structure has application in the classroom. Certain ideas appear to be so fundamental to understanding light, scale, and gravity that no headway can be made until they are mastered. If we learn to set realistic goals for our students and teach the prerequisite notions prior to the more exotic ones, we may be able to optimize student learning and build understanding that outlasts the final exam. 